\title{
Strength Training Affects Lower Extremity Gait Kinematics, Not Kinetics, in People With Diabetic Polyneuropathy
}

Citation for published version (APA):

Melai, T., Schaper, N. C., ljzerman, T. H., Willems, P. J. B., De Lange, T. L. H., Meijer, K., Lieverse, A. G., \& Savelberg, H. H. C. M. (2014). Strength Training Affects Lower Extremity Gait Kinematics, Not Kinetics, in People With Diabetic Polyneuropathy. Journal of Applied Biomechanics, 30(2), 221-230. https://doi.org/10.1123/jab.2013-0186

Document status and date:

Published: 01/04/2014

DOI:

10.1123/jab.2013-0186

Document Version:

Publisher's PDF, also known as Version of record

\section{Document license:}

Taverne

Please check the document version of this publication:

- A submitted manuscript is the version of the article upon submission and before peer-review. There can be important differences between the submitted version and the official published version of record.

People interested in the research are advised to contact the author for the final version of the publication, or visit the DOI to the publisher's website.

- The final author version and the galley proof are versions of the publication after peer review.

- The final published version features the final layout of the paper including the volume, issue and page numbers.

Link to publication

\footnotetext{
General rights rights.

- You may freely distribute the URL identifying the publication in the public portal. please follow below link for the End User Agreement:

www.umlib.nl/taverne-license

Take down policy

If you believe that this document breaches copyright please contact us at:

repository@maastrichtuniversity.nl

providing details and we will investigate your claim.
}

Copyright and moral rights for the publications made accessible in the public portal are retained by the authors and/or other copyright owners and it is a condition of accessing publications that users recognise and abide by the legal requirements associated with these

- Users may download and print one copy of any publication from the public portal for the purpose of private study or research.

- You may not further distribute the material or use it for any profit-making activity or commercial gain

If the publication is distributed under the terms of Article $25 \mathrm{fa}$ of the Dutch Copyright Act, indicated by the "Taverne" license above, 


\title{
Strength Training Affects Lower Extremity Gait Kinematics, Not Kinetics, in People With Diabetic Polyneuropathy
}

\author{
Tom Melai, ${ }^{1,2}$ Nicolaas C. Schaper, ${ }^{2}$ T. Herman IJzerman, ${ }^{2}$ Paul J.B. Willems ${ }^{2}$, \\ Ton L.H. de Lange, ${ }^{3}$ Kenneth Meijer, ${ }^{2}$ Aloysius G. Lieverse,${ }^{4}$ and Hans H.C.M. Savelberg ${ }^{2}$ \\ ${ }^{1}$ Fontys University of Applied Sciences, Eindhoven; ${ }^{2}$ Maastricht University Medical Centre; \\ ${ }^{3} \mathrm{ADL}$ Biomechanical Consultancy, Rosmalen; ${ }^{4}$ Maxima Medical Centre, Eindhoven
}

\begin{abstract}
Increased forefoot loading in diabetic polyneuropathy plays an important role in the development of plantar foot ulcers and can originate from alterations in muscle strength, joint moments and gait pattern. The current study evaluated whether strength training can improve lower extremity joint moments and spatiotemporal gait characteristics in patients with diabetic polyneuropathy. An intervention group receiving strength training during 24 weeks and a control group receiving no intervention. Measurements were performed in both groups at $t=0, t=12, t=24$ and $t=52$ weeks at an individually preferred and standardized imposed gait velocity. The strength training did not affect the maximal amplitude of hip, knee and ankle joint moments, but did result in an increase in stance phase duration, stride time and stride length of approximately $5 \%$, during the imposed gait velocity. In addition, both groups increased their preferred gait velocity over one year. Future longitudinal studies should further explore the possible effects of strength training on spatiotemporal gait characteristics. The current study provides valuable information on changes in gait velocities and the progressive lower extremity problems in patients with polyneuropathy.
\end{abstract}

Keywords: physical therapy, gait, stride length, joint moments, plantar loading

People with diabetic polyneuropathy (DPN) experience higher loading of the forefoot, which is a risk factor for the development of ulcers. ${ }^{1}$ Several authors suggested that the presence of muscle weakness or limitations in motor control could play a role in the development of this increased forefoot loading. ${ }^{2-4}$ In a previous study $^{5}$ we found a higher ankle plantar flexion moment during the first half of the stance phase in DPN patients with higher loading of the forefoot. In these patients a faster forward displacement of the point of application of the ground reaction force (GRF) concurred with an increase of the internal ankle plantar flexion moment and a decrease of the internal knee extension moment. ${ }^{5}$ In a subsequent study we observed strong positive associations between the internal ankle plantar flexion moment, the roll-off of the foot and forefoot loading. ${ }^{6}$ The dorsal flexors play an important role in decelerating the plantar flexion movement just after heel strike and the plantar flexors limit forward displacement of the tibia by eccentric contraction in late mid stance, causing delayed forward displacement of center of pressure and thereby limiting the plantar flexion moment. Therefore, we hypothesized that muscle weakness of these muscle groups and limitations in motor control result in patients with
DPN in an impaired ability to compensate the ankle plantar flexion moment during gait, leading to higher forefoot loading. In addition to the changes in joint moments, also changes in spatiotemporal gait characteristics can influence plantar loading in DPN. ${ }^{7}$ People with DPN have a lower gait velocity, take smaller steps and have a longer stride duration, ${ }^{8,9}$ which can lead to lower peak pressures. These changes in spatiotemporal gait characteristics can be a result of muscle weakness or limitations in motor control and will, in part, counterbalance the effects of the altered joint moments, as this would lead to a lower loading of the forefoot.

We hypothesize that improving lower extremity muscle strength should enable a better control of the roll-off of the foot, a slower forward displacement of the point of application of the GRF and consequently a lower ankle plantar flexion moment during the first part of the stance phase and a higher knee extension moment. Therefore, the aim of the current study was to evaluate the effects of strength training on lower extremity joint moments in patients with DPN. As the training might lead to changes in spatiotemporal gait characteristics, which can influence joint moments, also the effects on gait velocity, stance phase duration, stride length and

Tom Melai is with the Department of Health Innovation \& Technology, Institute of Allied Health Professions, Fontys University of Applied Sciences, Eindhoven, The Netherlands, and with the Department of Human Movement Sciences, NUTRIM School for Nutrition, Toxicology and Metabolism, Maastricht University Medical Centre, Maastricht, The Netherlands. Nicolaas C. Schaper is with the Department of Internal Medicine, CAPHRI Institute Maastricht, Maastricht University Medical Centre, Maastricht, The Netherlands. T. Herman IJzerman is with the Department of Human Movement Sciences, NUTRIM School for Nutrition, Toxicology and Metabolism, Maastricht University Medical Centre, Maastricht, The Netherlands. Paul J.B. Willems is with the Department of Human Movement Sciences, NUTRIM School for Nutrition, Toxicology and Metabolism, Maastricht University Medical Centre, Maastricht, The Netherlands. Ton L.H. de Lange is with ADL Biomechanical Consultancy, Rosmalen, The Netherlands. Kenneth Meijer is with the Department of Human Movement Sciences, NUTRIM School for Nutrition, Toxicology and Metabolism, Maastricht University Medical Centre, Maastricht, The Netherlands. Aloysius G. Lieverse is with the Department of Internal Medicine, Maxima Medical Centre, Eindhoven, The Netherlands. Hans H.C.M. Savelberg is with the Department of Human Movement Sciences, NUTRIM School for Nutrition, Toxicology and Metabolism, Maastricht University Medical Centre, Maastricht, The Netherlands. Address author correspondence to Hans H.C.M. Savelberg at hans.savelberg@maastrichtuniversity.nl. 
stride duration were evaluated. In addition, as gait velocity is an important confounder of joint moments and spatiotemporal gait characteristics, current study was performed at both a preferred and a standardized, imposed gait velocity.

\section{Methods}

This study was part of a randomized controlled multicenter trial (registration: NCT00759265) with two different study sites, both in the southern part of the Netherlands.

\section{Participants}

Participants were recruited from five diabetes outpatient clinics (one university and four regional hospitals) and all measurements were performed at two study sites. Participants had to be able to walk independently for six minutes and had to be between 50 and 80 years of age, to create a homogenous group of patients with type 2 diabetes. Participants were excluded if diagnosed with severe cardiac disease, renal dysfunction (creatinin $>180 \mu \mathrm{mol} / \mathrm{L}$ ), intermittent claudication, neurological disorders other than DPN, rheumatoid arthritis, severe osteoarthritis, foot deformities, amputations or foot ulceration. Participants needed to be able to participate in gait experiments without risk of falling, which was assessed by the research staff. The diagnosis of DPN was made in 94 participants, scoring at least 4 points out of the maximal 33 during a standardized Clinical Neurological Examination (CNE), which included reflexes, light touch, vibration, position sense, pinprick and lower extremity muscle strength testing. ${ }^{10}$

At each study site, using sealed envelopes, the participants were randomized to the intervention group, receiving strength training or to the control group receiving no training (Figure 1). Both groups were free to perform any additional physical activity or training outside the trial.

\section{Intervention}

Patients assigned to the intervention received a weekly plenary training, which was designed based on scarce literature and multidisciplinary consensus, ${ }^{11}$ aiming to improve motor control and muscle strength of the lower extremity in a 24 weeks program guided by a physical therapist. In the first 12 weeks (part one) the training focused on the muscles around the ankle. During the next 12 weeks (part two) also the muscles around the knee were trained.

Each plenary training session lasted one and a half hour and started with a warm up by simple exercises during gait, followed by lower extremity muscle strength training. Resistance was built up from low-to-moderate intensity at $40-60 \%$ of one repeated maximum, based on the number of repetitions until fatigue, using elastic bands, weight vests and ankle weights. In addition, small coordinative tasks (eg, moving objects with their feet, narrow based walking) were performed to train motor control of the lower extremity. During part one of the training, especially dorsal and plantar flexion strength were trained in isolated and chained conditions. During part two, also training of knee extension and flexion strength were added. Next, participants received gait training on an obstacle course, set up to resemble activities of daily life. The plenary training session was concluded with a selection of various interactive, tailor fit games. In addition to the supervised sessions once a week, participants were asked to carry on two times a week the muscle strength training exercises at home. More information on the training program is provided in a supplementary document.

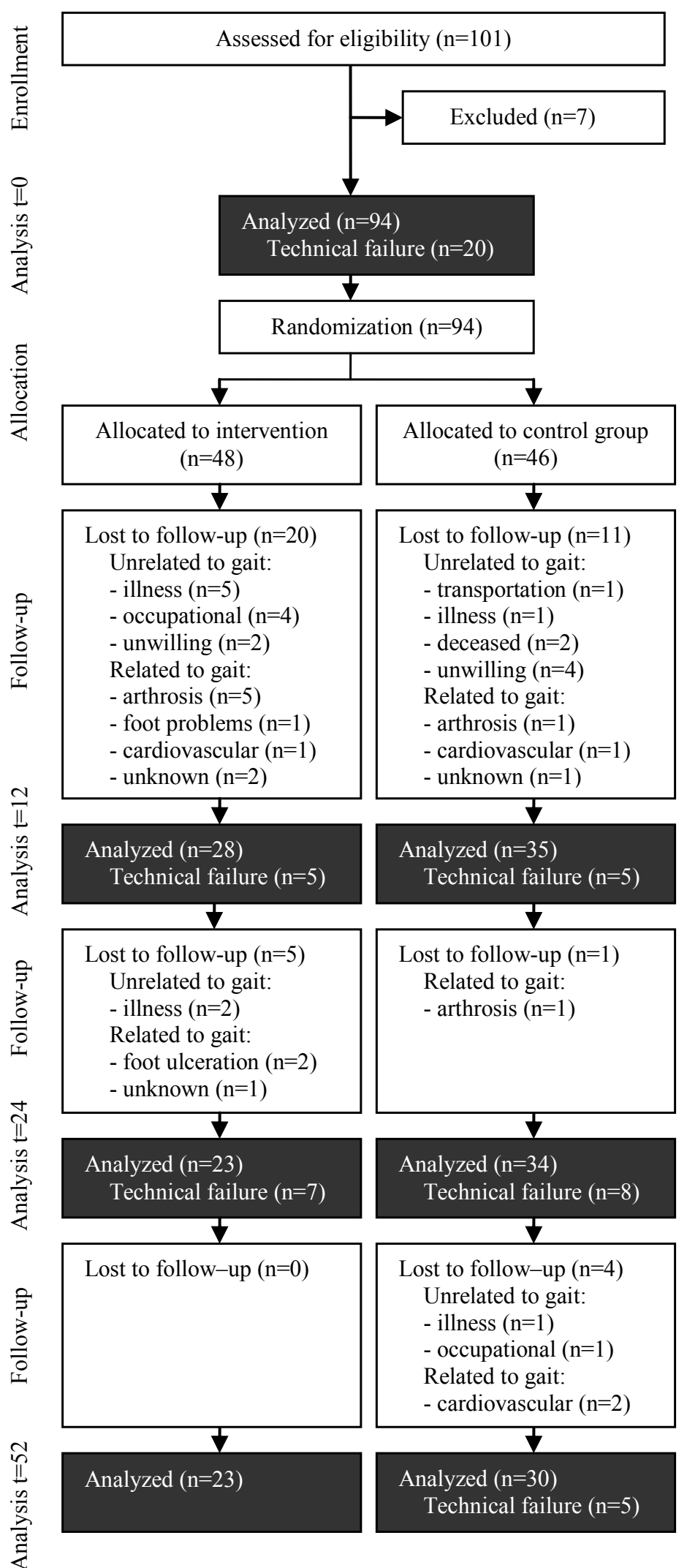

Figure 1 - Flowchart illustrating the study design, the number of participants analyzed at different times of measurement (at $t=0,12,24$ and 52 weeks) and attrition due to technical failure (eg, incomplete marker sets, interference of the other foot). Loss of follow-up was specified with reason for drop out, which was classified as related or unrelated to gait. 


\section{Experimental Setup}

At both study sites a seven meter wooden walkway with an embedded force platform was used; at one site an AMTI force platform was used (AMTI LG6_2-1, Advanced Medical Technology Inc, Newton, MA, US) and at the other site a Kistler platform was available (9281 A SN, Kistler Instrumente AG, Winterhur, Switzerland). Throughout the study, each subject was measured at the same institute and with the same platform. At both sites the same digital high-speed camera (1.3 megapixel Pixellink PL-A741, sampling at $100 \mathrm{~Hz}$ ) recorded the $2 \mathrm{D}$ position of the reflective markers in the sagittal plane. These markers were attached to the skin at the middle of the greater trochanter, lateral femoral epicondyle, calcaneus, lateral malleolus and fifth metatarsal of the right leg of each subject, as described earlier. ${ }^{5}$ Average horizontal displacement of the marker on the greater trochanter was used to determine gait velocity. An indication of gait velocity during the trial was obtained by means of photocells placed over the platform. Spatiotemporal gait characteristics were determined using a triaxial accelerometer (MT-9, Xsense, Enschede, the Netherlands) that was attached to the participants' sacrum by means of double layered tape.

\section{Measurement Protocol}

The protocol was approved by the medical ethical committee of Maastricht University Medical Centre and all participants signed an informed consent.

Participants were asked to walk with bare feet over the test track as naturally as possible. A trial was successful if the participants did not alter their gait pattern to target the platform with their right foot. After completing five successful trials at their preferred gait velocity, participants were asked to complete again five successful trials at a standardized, imposed gait velocity at $1.2 \mathrm{~m} / \mathrm{s}$, as this resembles the preferred gait velocity for this age group. ${ }^{5}$ For practical reasons we allowed a range in gait velocity of $\pm 0.1 \mathrm{~m} / \mathrm{s}$.

Participants were measured at baseline before randomization $(t$ $=0)$, at 12 weeks $(t=12)$, after the first part of the intervention, at 24 weeks $(t=24)$ after the second part of the intervention, and after 52 weeks at follow up $(t=52)$. Due to practical reasons it was not possible to perform measurements by research staff blinded for treatment allocation. When a subject choose to cease their participation, they were asked to report the reason (if they wished so), the reasons for withdrawal were classified as either gait or not gait related.

As hyperglycemia can affect muscle performance, ${ }^{12}$ fasting blood glucose and glycated hemoglobin, HbA1c, were measured at $t=0, t=24$ and $t=52$.

\section{Analysis}

The primary outcome measures for this study were the effects of the strength-training program on lower limb gait characteristics, including joint moments, stance phase duration, stride length and stride duration. The effects of time, age, body mass and sex on these parameters were secondary outcome measures.

An inverse dynamics approach was used to obtain internal joint moments. ${ }^{5}$ For characterization of individual joint moments, maximal internal extension and flexion moments at hip (H-ext, H-flex), knee (K-ext, K-flex) and ankle joint (A-plant) were determined. Also the ankle plantar flexion moments at $40 \%$ of the stance phase (A-40) were assessed. To characterize the pattern of the ankle joint moment, the quotient of A-40 over A-plant was calculated (A-40/Aplant). Previous research indicated that this quotient discriminates well between people with and without DPN. ${ }^{5}$ As body mass is an important confounder of the forces applied during gait, all joint moments were normalized for body mass. ${ }^{13}$

Stance phase duration was defined as the contact time of the right foot on the force platform. The time between two successive peaks of the vertical acceleration signal and gait velocity were used to calculate stride length and stride duration.

The average of each variable was determined using a minimum of three correct trials per subject per time of measurement.

\section{Statistical Analysis}

SPSS 15.0 for Windows was used for data analysis. Data are presented as mean with either standard deviation or $95 \%$ confidence interval (CI). A random intercept model was fitted to evaluate the effect of the intervention and changes in gait characteristics over time, adjusting simultaneously for covariates. Velocity was not entered into the model as not all participants were able to complete the imposed gait velocity. Therefore, analysis was performed separately for both the preferred and imposed gait velocity. Age, gender, body mass and group were entered as fixed factors for model estimation of the spatiotemporal gait parameters. If not significant, the factor body mass was left out of the model estimation for joint moments as these already included a correction for this factor. The random factor was made up by the participants. An interaction term between group and time was considered for all parameters to test whether temporal changes of the outcomes over time depended on the intervention. In addition, the effect of study site on the interaction of group and time was explored to test whether this could have influenced the effect of the intervention. If this was not the case, study site was left out of the model. All fixed factors with exception of interaction of group and time, were always left in the model. Analyses were performed on an intention to treat basis and all available measurements were used for model estimation, including the measurements of the patients who dropped out. Differences were considered significant if $P \leq .05$. Estimates were determined by a restricted maximum likelihood method. As long as missing occurs at random, the advantage of the mixed model approach is that our analyses would not be affected by missing data and that the fixed effect parameters are unbiased. However, the pattern of missing data within the groups indicates that this condition may not hold. Significant differences should therefore be interpreted with caution. Finally, the outcome measures as reported in this article were secondary endpoints of a study of strength training on mobility in DPN.

\section{Results}

There were no baseline differences between the intervention and control group (IG and CG respectively, Table 1). Participants were elderly (IG 68.2 years, CG 65.5 years) with moderate DPN (CNE score; 12.9 and 13.0, respectively). Most of the participants were men (83 and 78\%), had moderate glycemic control (HbA1c; 7.3 and $7.3 \%$ ) and were overweight to obese (BMI; 30.2 and $30.9 \mathrm{~kg}$ / $\mathrm{m}^{2}$ ). Overall, participants did not experience changes in body mass during the study. At baseline, 16 participants (IG 8, CG 8) were not able to reach the imposed gait velocity, for these participants only measurements of their preferred gait velocity were analyzed. The number of participants that were not able to reach the faster, imposed velocity during the three follow up measurements was respectively 5, 2 and 4 for the intervention group, and 8, 5 and 2 for the control group. In 17 cases data could not be analyzed due to technical failure, such as incomplete marker sets or interference of the other foot (Figure 1). 
Table 1 Participant characteristics at baseline measurement

\begin{tabular}{lccc}
\hline & IG & CG & $\boldsymbol{P}$ value \\
\hline Age (years) & $68.2(7.3)$ & $65.5(7.4)$ & 0.962 \\
Sex (male/female) & $40 / 8$ & $36 / 10$ & 0.217 \\
Body height $(\mathrm{m})$ & $1.74(0.08)$ & $1.74(0.08)$ & 0.913 \\
Body mass $(\mathrm{kg})$ & $91.6(20.3)$ & $94.3(18.9)$ & 0.789 \\
BMI $\left(\mathrm{kg} / \mathrm{m}^{2}\right)$ & $30.2(6.3)$ & $30.9(4.9)$ & 0.190 \\
CNE score & $12.9(4.9)$ & $13.0(5.5)$ & 0.186 \\
HbA1c $(\%)$ & $7.3(1.1)$ & $7.3(1.1)$ & 0.796 \\
Glucose $(\mathrm{mmol} / \mathrm{L})$ & $8.8(2.6)$ & $8.2(2.0)$ & 0.426 \\
Creatinine $(\mu \mathrm{mol} / \mathrm{L})$ & $100.6(34.7)$ & $95.9(24.5)$ & 0.076 \\
\hline
\end{tabular}

Note. Means and standard deviation of the participants characteristics and biochemical analysis at baseline for both intervention and control group. Age determined at onset of study. Abbreviations: $\mathrm{CNE}=$ clinical neurological examination; $\mathrm{IG}=$ intervention group; $\mathrm{CG}=$ control group.

Dropout was high in both groups, especially during the first 12 weeks (IG 41.7\%; CG 22.2\%). The reasons for dropout are reported in Figure 1. Gait related reasons were reported for 8 of the 20 participants that stopped with the intervention during the first 12 weeks. In the control group this was 2 out of 10 . Throughout the complete study 25 participants stopped the intervention of which 11 reported gait related problems. In the control group 5 out of 15 participants dropped out due to such problems. Probably due to the relative small number of participants for chi-square analysis, no significant differences between the 2 groups were observed in drop-outs.

In comparison with the $C G$ patients, the training program resulted in the IG patients in an increase in stride length of 5.1\% ( $0.065 \mathrm{~m}, P \leq .04$, Table and Figure 2d), in stance phase duration of $5.5 \%(0.035 \mathrm{~s}, P \leq .01$, Table and Figure $2 \mathrm{f})$ and in stride time of $5.6 \%(0.058 \mathrm{~s}, P \leq .01$, Table and Figure $2 \mathrm{~h})$ determined during the standardized, imposed gait velocity. For the other variables, no differences between the CG and IG patients were observed after baseline, in particular, no differences were observed in joint moments. As training did not affect these variables, an interaction effect was not included in the model studying these parameters. In addition, no interaction of study site with group status was observed; it was therefore left out of the model as well.

Regardless of the effect of the training program, effects of time on the CG and IG groups combined were present for several parameters, suggesting either a learning effect and/or deterioration over time. After 52 weeks, both the intervention and control group walked $8.8 \%$ faster under the preferred gait velocity condition $\left(0.093 \mathrm{~m} \cdot \mathrm{s}^{-1}, P<.001\right.$, Figure and Table 2a), taking 5.3\% larger strides $(0.063 \mathrm{~m}, P<.001$, Figure and Table $2 \mathrm{c})$ in $3.7 \%$ less time $\left(0.043 \mathrm{~m} \cdot \mathrm{s}^{-1}, P \leq .01\right.$, Figure and Table $\left.2 \mathrm{~g}\right)$. A-40 increased with $8.6 \%$ during the preferred gait velocity $\left(0.062 \mathrm{~N} \cdot \mathrm{m} \cdot \mathrm{kg}^{-1}, P \leq .01\right.$, Figure and Table 3i). In addition, the maximal hip joint extension moment increased with $15.2 \%\left(0.097 \mathrm{~N} \cdot \mathrm{m} \cdot \mathrm{kg}^{-1}, P \leq .01\right.$, Figure and Table $3 \mathrm{a}$ ) and the maximal hip joint flexion moment increased with $21.6 \%\left(0.112 \mathrm{~N} \cdot \mathrm{m} \cdot \mathrm{kg}^{-1}, P \leq .01\right.$, Figure and Table $\left.3 \mathrm{c}\right)$ in our patients irrespective of their training status during the preferred gait velocity after 52 weeks. Also maximal knee extension moment increased with $33.8 \%$ during the preferred gait velocity $\left(0.149 \mathrm{~N} \cdot \mathrm{m} \cdot \mathrm{kg}^{-1}, P\right.$ $<.001$, Figure and Table $3 \mathrm{e}$ ) and $19.4 \%$ during the imposed gait velocity $\left(0.102 \mathrm{~N} \cdot \mathrm{m} \cdot \mathrm{kg}^{-1}, P<.001\right.$, Figure and Table $\left.3 \mathrm{f}\right)$, while maximal knee flexion moment decreased with $47.5 \%$ during the preferred gait velocity $\left(0.089 \mathrm{~N} \cdot \mathrm{m} \cdot \mathrm{kg}^{-1}, P<.001\right.$, Figure and Table $3 \mathrm{~g})$ and $55.2 \%$ during the imposed gait velocity $\left(0.109 \mathrm{~N} \cdot \mathrm{m} \cdot \mathrm{kg}^{-1}\right.$, $P<.001$, Figure and Table 3h).

Age, body mass and sex were found to influence joint moments and spatial temporal gait characteristics in our multivariate model. Other covariates did not significantly affect the studied parameters.
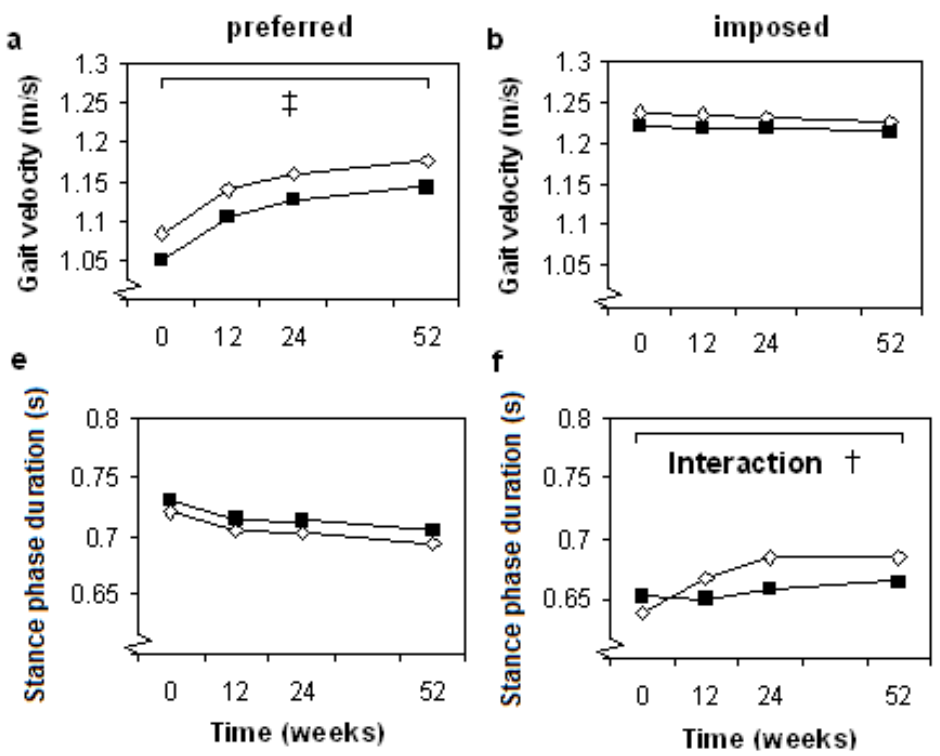

Figure 2 - (a-h) Estimated mean values of spatiotemporal gait characteristics over time for intervention and control groups, according to the final random intercept models (Table 3). Significant time effects over 52 weeks and interaction effects are marked thus: $* P \leq .05, \dagger P \leq .01, \ddagger P \leq .001$.
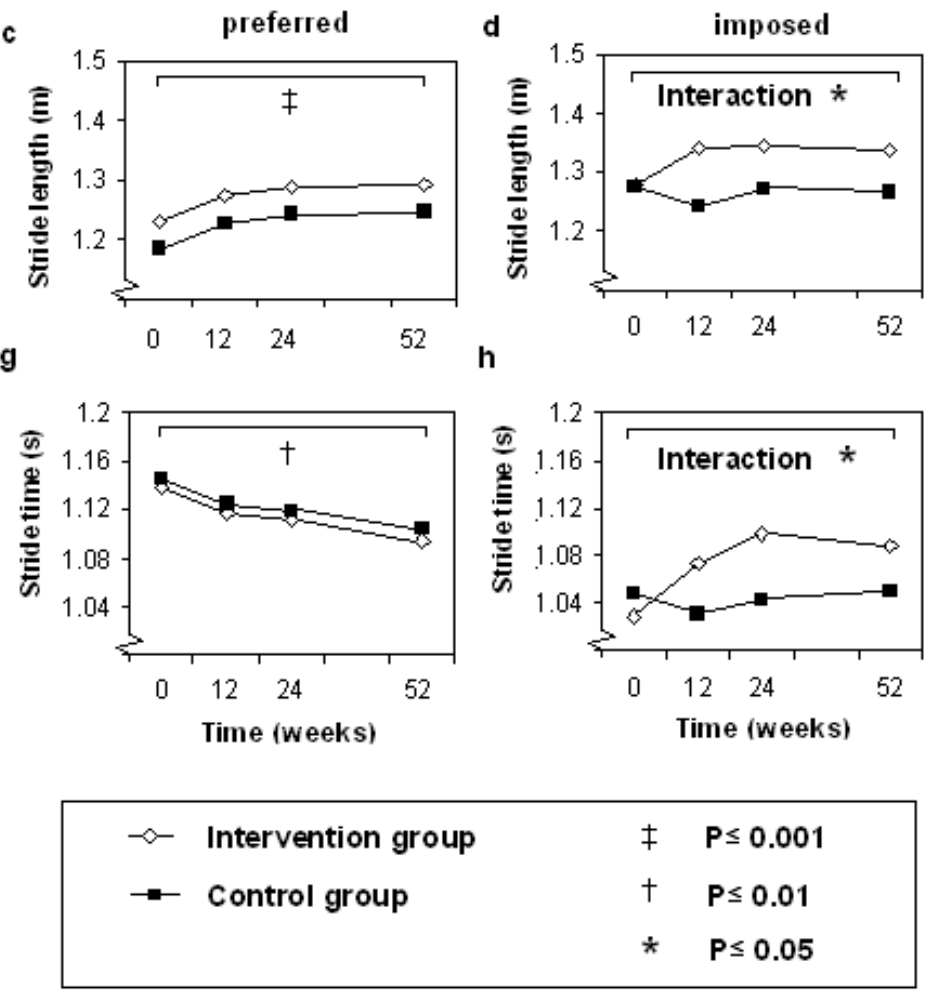
Table 2 (a-n): The determinants and their effects on spatiotemporal gait characteristics in diabetic patients with polyneuropathy depicted as $\beta(\mathrm{Cl} 95)$

\begin{tabular}{|c|c|c|c|c|}
\hline & Preferred & Imposed & Preferred & Imposed \\
\hline & a. Gait Velocity $(\mathrm{m} / \mathrm{s})$ & b. Gait Velocity (m/s) & c. Stride Length (m) & d. Stride Length (m) \\
\hline Intercept & $1.849(1.502,2.197) \ddagger$ & $1.322(1.185,1.458) \ddagger$ & $1.766(1.453,2.080) \ddagger$ & $1.494(1.225,1.764) \ddagger$ \\
\hline Age (years) & $-.008(-.012,-.004) \ddagger$ & $-.001(-.003, .000)$ & $-.006(-.010,-.002) \dagger$ & $-.003(-.007, .000)$ \\
\hline Gender (F/M) & $-.027(-.117, .062)$ & $-.008(-.041, .024)$ & $.001(-.080, .083)$ & $.008(-.058, .075)$ \\
\hline Body mass (kg) & $-.002(-.004, .000)$ & $-.000(-.001, .001)$ & $-.001(-.003, .000)$ & $.000(-.002, .001)$ \\
\hline Group (IG vs CG) & $.034(-.025, .093)$ & $.016(-.008, .038)$ & $.047(-.007, .100)$ & $.069(.009, .129) \dagger$ \\
\hline Time $t=0$ vs 52 & $-.093(-.135,-.052) \ddagger$ & $.010(-.011, .032)$ & $-.063(-.097, .029) \ddagger$ & $.006(-.035, .047)$ \\
\hline Time $t=12$ vs 52 & $-.037(-.079,-.006)$ & $.008(-.014, .030)$ & $-.021(-.055, .014)$ & $-.026(-.066, .015)$ \\
\hline Time $t=24$ vs 52 & $-.016(-.060, .028)$ & $.007(-.016, .029)$ & $-.004(-.040, .032)$ & $.003(-.038, .043)$ \\
\hline Group $\times$ Time $t=0$ vs 52 & & & & $-.065(-.125,-.005)^{*}$ \\
\hline Group $\times$ Time $t=12$ vs 52 & & & & $.031(-.031, .093)$ \\
\hline Group $\times$ Time $t=24$ vs 52 & & & & $.004(-.059,066)$ \\
\hline$\sigma_{i}^{2}$ & $.010(.008, .013) \neq$ & $.002(.002, .003) \ddagger$ & $.007(.005, .009) \ddagger$ & $.004(.003, .006) \neq$ \\
\hline \multirow[t]{2}{*}{$\sigma_{b 0}^{2}$} & $.015(.010, .023) \ddagger$ & $.001(.001, .003) \dagger$ & $.013(.009, .020) \ddagger$ & $.008(.005,0.13) \neq$ \\
\hline & $\begin{array}{c}\text { e. Stand Phase } \\
\text { Duration (s) }\end{array}$ & $\begin{array}{l}\text { f. Stand Phase } \\
\text { Duration (s) }\end{array}$ & g. Stride Time (s) & h. Stride Time (s) \\
\hline Intercept & $.435(.266, .604) \ddagger$ & $.701(.580, .823) \ddagger$ & $.797(.571,1.02) \ddagger$ & $1.144(.963,1.325) \ddagger$ \\
\hline Age (years) & $.003(.001, .005) \dagger$ & $-.001(-.002, .001)$ & $.004(.001, .006) \dagger$ & $-.001(-.004, .001)$ \\
\hline Gender (F/M) & $.023(-.020, .067)$ & $.012(-.018, .042)$ & $.044(-.015, .102)$ & $.016(-.028, .060)$ \\
\hline Body mass (kg) & $.001(-.000, .002)$ & $.000(-.001, .001)$ & $.000(-.001, .002)$ & $-.000(-.001, .001)$ \\
\hline Group (IG vs CG) & $-.010(-.039, .019)$ & $.021(-.005, .048)$ & $-.008(-.046, .031)$ & $.038(-.004, .080)$ \\
\hline Time $t=0$ vs 52 & $.027(.007, .047)$ & $-.011(-.029, .007)$ & $.043(.015, .070) \dagger$ & $-.002(-.033, .028)$ \\
\hline Time $t=12$ vs 52 & $.011(-.010, .031)$ & $-.013(-.030, .005)$ & $.022(-.006, .050)$ & $-.020(-.050, .010)$ \\
\hline Time $t=24$ vs 52 & $.008(-.013, .030)$ & $-.005(-.023, .012)$ & $.016(-.013, .045)$ & $-.007(-.037, .023)$ \\
\hline Group $\times$ Time $t=0$ vs 52 & & $-.035(-.061, .008) \dagger$ & & $-.058(-.102,-.014)^{*}$ \\
\hline Group $\times$ Time $t=12$ vs 52 & & $-.004(-.031, .023)$ & & $-.006(-.040, .052)$ \\
\hline Group $\times$ Time $t=24$ vs 52 & & $.005(-.023, .032)$ & & $.017(-.029, .064)$ \\
\hline$\sigma_{i}^{2}$ & $.002(.002, .003) \ddagger$ & $.001(.001, .001) \ddagger$ & $.005(.004, .006) \ddagger$ & $.002(.002, .003) \ddagger$ \\
\hline$\sigma_{b 0}^{2}$ & $.004(.002, .005) \ddagger$ & $.002(.001, .003) \ddagger$ & $.006(.004, .010) \ddagger$ & $.003(.002, .006) \ddagger$ \\
\hline
\end{tabular}

Note. Measurements were obtained at two gait velocities, preferred and imposed (see text). Estimated fixed (and random) effect parameters of the random intercept models are shown. $\beta(95 \% \mathrm{CI})$ represent average changes in the outcome variables per unit increase for the continuous explanatory variables. For categorical variables, the estimates represent average changes with respect to the reference (control group, females, or follow up measurement at $t=52$ weeks). Age was determined at onset of the study. Significant differences are marked thus: $* P \leq .05 ; \uparrow P \leq .01 ; \ddagger P \leq .001$. Abbreviations: $\mathrm{IG}=$ intervention group; $\mathrm{CG}=$ control group; $\mathrm{M}=$ male; $\mathrm{F}=$ female.

The maximal knee joint flexion moment was lower for older participants, every extra year of age at onset of the study concurred with a $3.2 \%$ significantly smaller maximal knee joint flexion moment during the preferred gait velocity $\left(0.006 \mathrm{~N} \cdot \mathrm{m} \cdot \mathrm{kg}^{-1}, P=\right.$ .02 , Figure and Table $3 \mathrm{~g}$ ). A higher age at onset of the study was associated with a reduction of A-plant of $0.6 \%\left(0.009 \mathrm{~N} \cdot \mathrm{m} \cdot \mathrm{kg}^{-1}, P\right.$ $<.001$, Figure and Table 3k) and $0.7 \%\left(0.010 \mathrm{~N} \cdot \mathrm{m} \cdot \mathrm{kg}^{-1}, P<.001\right.$, Figure and Table 31) per year for the preferred and imposed gait velocity respectively. Consequently, A-40 / A-plant increased with aging also with $1.0 \%$ at the preferred $(0.005, P \leq .01$, Figure and Table $3 \mathrm{~m})$ and $1.3 \%$ at the imposed gait velocity $(0.006, P \leq .01$, Figure and Table $3 \mathrm{n})$. The preferred gait velocity decreased with $0.7 \%\left(0.008 \mathrm{~m} \cdot \mathrm{s}^{-1}, P<.001\right.$, Figure and Table $\left.2 \mathrm{a}\right)$, stride length decreased with $0.5 \%(0.006 \mathrm{~m}, P<.001$, Figure and Table $2 \mathrm{c})$ and stance phase duration and stride time both increased with $0.4 \%$ ( 0.003 and 0.004 s respectively, $P \leq .01$, Figure and Table $2 \mathrm{e}$ and g) for every extra year of age.
People with a higher body mass experienced a proportionally lower, maximal knee joint flexion moment during the imposed gait velocity of $1.5 \%$ per $\mathrm{kg}$ of body mass $\left(0.003 \mathrm{~N} \cdot \mathrm{m} \cdot \mathrm{kg}^{-1}, P \leq .01\right.$, Figure and Table $3 \mathrm{~h}$ ) and proportionally lower maximum ankle plantar flexion moments of $0.2 \%$ per kilogram of body mass at both gait velocities $\left(0.003 \mathrm{~N} \cdot \mathrm{m} \cdot \mathrm{kg}^{-1}, P \leq .01\right.$, Figure and Table $3 \mathrm{k}$ and 1$)$.

Corrected for body mass, the women in this study had a higher maximum ankle plantar flexion moment compared with the men of 8.0 and $7.5 \%$ for the preferred and imposed gait velocity respectively $\left(0.115 \mathrm{~N} \cdot \mathrm{m} \cdot \mathrm{kg}^{-1}, P=.02 ; 0.119 \mathrm{~N} \cdot \mathrm{m} \cdot \mathrm{kg}^{-1}, P=.03\right.$, Figure and Table $3 \mathrm{k}$ and $\mathrm{l}$ ).

\section{Discussion}

The aim of the current study was to evaluate the effect of strength training on lower extremity joint moments and spatiotemporal gait characteristics in patients with DPN. We hypothesized that improving 
Table 3 (a-n): The determinants and their effects on gait dynamics in diabetic patients with polyneuropathy depicted as $\beta(\mathrm{Cl} 95)$

\begin{tabular}{|c|c|c|c|c|}
\hline & Preferred & Imposed & Preferred & Imposed \\
\hline & a. H-ext $(\mathrm{N} \cdot \mathrm{m} / \mathrm{kg})$ & b. H-ext (N·m/kg) & c. $\mathrm{H}$-flex $(\mathrm{N} \cdot \mathrm{m} / \mathrm{kg})$ & d. H-flex (N.m/kg) \\
\hline Intercept & $.543(.125, .961)^{*}$ & $.395(-.067, .816)$ & $1.053(-1.592,-.514) \ddagger$ & $.774(-1.409,-.139)^{*}$ \\
\hline Age (years) & $.003(-.003, .009)$ & $.006(-.001, .013)$ & $-.006(-.002, .013)$ & $-.002(-.007, .011)$ \\
\hline Gender (F/M) & $.041(-.070, .151)$ & $.031(-.080, .142)$ & $-.036(-.109, .180)$ & $.071(-.237, .094)$ \\
\hline \multicolumn{5}{|l|}{ Body mass (kg) } \\
\hline Group (IG vs CG) & $-.031(-.116, .054)$ & $-.047(-.136, .042)$ & $-.070(-.039, .179)$ & $-.018(-.109, .145)$ \\
\hline Time $t=0$ vs 52 & $-.097(-.170,-.025) \dagger$ & $-.034(-.110, .041)$ & $-.112(.033, .190) \dagger$ & $-.055(-.026, .136)$ \\
\hline Time $t=12$ vs 52 & $-.037(-.113, .039)$ & $-.026(-.104, .053)$ & $-.093(.012, .174)^{*}$ & $-.119(.037, .201) \dagger$ \\
\hline Time $t=24$ vs 52 & $.034(-.045, .113)$ & $.006(-.074, .086)$ & $.005(-.089, .079)$ & $.035(-.117, .048)$ \\
\hline$\sigma^{2}{ }_{i}$ & $.033(.026, .043) \ddagger$ & $.030(.023, .040) \ddagger$ & $.038(.029, .048) \ddagger$ & $.032(.024, .042)$ \\
\hline \multirow{2}{*}{$\sigma_{b 0}^{2}$} & $.024(.014, .042) \ddagger$ & $.023(.012, .042) \ddagger$ & $.050(.033, .075) \ddagger$ & $.068(.045, .102)$ \\
\hline & e. $\mathrm{K}$-ext $(\mathrm{N} \cdot \mathrm{m} / \mathrm{kg})$ & f. K-ext (N·m/kg) & g. K-flex $(\mathrm{N} \cdot \mathrm{m} / \mathrm{kg})$ & h. K-flex (N.m/kg) \\
\hline Intercept & $.655(-1.013,-.297) \dagger$ & $.513(-.910,-.115)^{*}$ & $.503(.126, .879) \dagger$ & $.698(.227,1.169) \dagger$ \\
\hline Age (years) & $-.001(-.005, .006)$ & $.002(-.008, .004)$ & $-.006(-.012,-.001)^{*}$ & $-.005(-.011, .001)$ \\
\hline Gender (F/M) & $-.044(-.052, .140)$ & $.025(-.078, .128)$ & $.021(-.082, .124)$ & $.067(-.050, .184)$ \\
\hline Body mass (kg) & & & & $-.003(-.006,-.001) *$ \\
\hline Group (IG vs CG) & $.002(-.074, .071)$ & $-.009(-.070, .089)$ & $.039(-.036, .115)$ & $.012(-.067, .092)$ \\
\hline Time $t=0$ vs 52 & $-.149(.096, .202) \ddagger$ & $-.102(.051, .154) \ddagger$ & $.089(.045, .134) \ddagger$ & $.109(.060, .158) \ddagger$ \\
\hline Time $t=12$ vs 52 & $-.057(.003, .112)^{*}$ & $-.025(-.027, .078)$ & $.037(-.009, .082)$ & $.035(-.015, .085)$ \\
\hline Time $t=24$ vs 52 & $-.015(-.041, .072)$ & $-.017(-.036, .070)$ & $.003(-.044, .050)$ & $-.007(-.057, .043)$ \\
\hline$\sigma_{i}^{2}$ & $.017(.013, .022) \ddagger$ & $.013(.010, .017) \ddagger$ & $.012(.009, .015) \ddagger$ & $.012(.009, .015) \ddagger$ \\
\hline \multirow[t]{2}{*}{$\sigma_{b 0}^{2}$} & $.022(.014, .033) \ddagger$ & $.026(.017,0.39) \ddagger$ & $.029(.020, .042) \ddagger$ & $.027(.018, .041) \ddagger$ \\
\hline & i. A-40 (N.m/kg) & j. A-40 (N.m/kg) & k. A-plant (N·m/kg) & I. A-plant (N.m/kg) \\
\hline Intercept & $.4777(.127, .828) \dagger$ & $.406(.020, .791)^{*}$ & $2.359(1.993,2.725) \ddagger$ & $2.439(2.016,2.863)$ \\
\hline Age (years) & $.004(-.001, .009)$ & $.005(-.001, .011)$ & $-.009(-.013,-.004) \ddagger$ & $-.010(-.015,-.005)$ \\
\hline Gender (F/M) & $.066(-.030, .161)$ & $.083(-.017, .183)$ & $.115(.021, .208) \dagger$ & $.119(.015, .222)^{*}$ \\
\hline Body mass (kg) & & & $-.003(-.005,-.001) \dagger$ & $-.003(-.006,-.001) \dagger$ \\
\hline Group (IG vs CG) & $-.006(-.076, .065)$ & $.027(-.051, .104)$ & $.038(-.024, .101)$ & $.020(-.052, .092)$ \\
\hline Time $t=0$ vs 52 & $-.062(-.105,-.018) \dagger$ & $-.053(-.104,-.003)$ & $-.030(-.077, .016)$ & $-.015(-.068, .037)$ \\
\hline Time $t=12$ vs 52 & $-.029(-.073, .015)$ & $-.031(-.082, .020)$ & $.003(-.048, .048)$ & $.005(-.048, .059)$ \\
\hline Time $t=24$ vs 52 & $-.027(-.073, .019)$ & $-.007(-.059, .045)$ & $.016(-.034, .066)$ & $.018(-.036, .072)$ \\
\hline$\sigma_{i}^{2}$ & $.011(.009, .014) \ddagger$ & $.012(.009, .016) \ddagger$ & $.013(.010, .017) \ddagger$ & $.014(.010, .018) \ddagger$ \\
\hline \multirow[t]{2}{*}{$\sigma_{b 0}^{2}$} & $.024(.017, .035) \ddagger$ & $.024(.016, .037) \ddagger$ & $.015(.010, .024) \ddagger$ & $.019(.012, .030) \ddagger$ \\
\hline & m. A-40 / A-Plant & n. A-40 / A-Plant & & \\
\hline Intercept & $.160(-.066, .387)$ & $.105(-.161, .372)$ & & \\
\hline Age (years) & $.005(.002, .008) \dagger$ & $.006(.002, .010) \dagger$ & & \\
\hline Gender (F/ M) & $.029(-.033, .091)$ & $.039(-.031, .109)$ & & \\
\hline \multicolumn{5}{|l|}{ Body mass (kg) } \\
\hline Group (IG vs CG) & $-.020(-.066, .025)$ & $.005(-.048, .059)$ & & \\
\hline Time $t=0$ vs 52 & $-.032(-.059,-.005)$ & $-.031(-.063, .000)$ & & \\
\hline Time $t=12$ vs 52 & $-.018(-.045, .010)$ & $-.020(-.052, .013)$ & & \\
\hline Time $t=24$ vs 52 & $-.020(-.049, .008)$ & $-.009(-.041, .023)$ & & \\
\hline$\sigma^{2}{ }_{i}$ & $.004(.003, .005) \ddagger$ & $.005(.004, .006) \ddagger$ & & \\
\hline$\sigma_{b 0}^{2}$ & $.010(.007, .015) \ddagger$ & $.013(.008, .019) \ddagger$ & & \\
\hline
\end{tabular}

Note. Significant differences are marked thus: ${ }^{*} P \leq 0.05 ; \dagger P \leq 0.01 ; \ddagger P \leq 0.001$. Abbreviations: $\mathrm{IG}=$ intervention group; $\mathrm{CG}=$ control group; $\mathrm{M}=$ male; $\mathrm{F}=\mathrm{Female}$. 

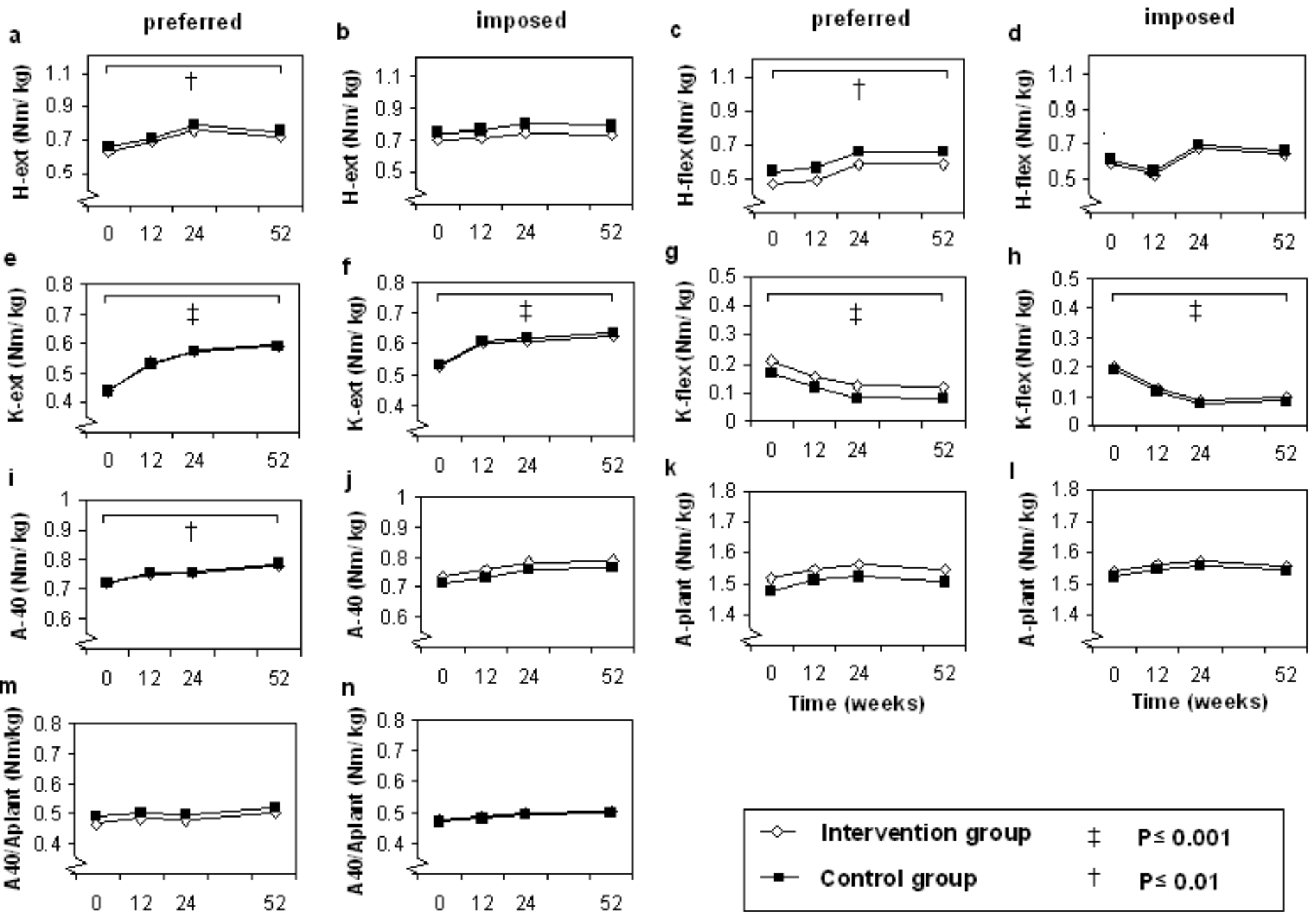

Figure 3 - $(a-n)$ Estimated mean values of gait dynamics over time for intervention and control groups, according to the final random intercept models (Table 2). Abbreviations: H-ext: maximal hip extension; H-flex: maximal hip flexion; K-flex: maximal knee flexion; K-ext: maximal knee extension. A-40: Plantar flexion moment at $40 \%$ of the stance phase; A-plant: Maximal plantar flexion moment. Significant time effects over 52 weeks and group differences are marked thus: $* P \leq .05, \uparrow P \leq .01, \ddagger P \leq .001$.

lower extremity muscle strength would enable a better control of the roll-off of the foot, a slower forward displacement of the point of application of the GRF and consequently a lower ankle plantar flexion moment during the first part of the stance phase and a higher knee extension moment, but the training did not influence joint moments in our patients and consequently it is to be expected that forefoot loading during a step was neither affected. However, the effect of the training could have been underestimated, as stride length increased, as discussed below. A larger stride length leads to a higher ankle plantar flexion moment which could have negated an effect of training on lowering the ankle plantar flexion moment. ${ }^{7}$ In addition, the intensity of the training program could have been too low to improve joint moments during gait. To be reported elsewhere, the training program did not increase maximal dorsal flexor strength, but did increase maximum plantar flexion strength (IJzerman et al, unpublished data). However, these data suggest that an increase in maximum plantar flexion did not influence the forces generated during gait. Alternatively, the lack of effect of the intervention on joint moments and maximum dorsal flection strength may have been caused by nerve damage so severe that a positive effect of a muscle-strengthening program was unattainable. It is also possible that the altered control of the roll-off of the foot in diabetic neuropathy does not so much depend on the result of loss of muscle strength, but more on other factors, such us joint motion, motor control, feedback from muscle spindles, rate of force development and sensory nerve function of the skin. $4,8,14,15$ The number of studies on the underlying mechanisms of gait alteration in DPN and especially on strength training in this population is to our knowledge very limited and our study can be one of the building blocks for future intervention studies in these patients.

To our knowledge, there is one published study on the effects of exercise on spatiotemporal gait characteristics in DPN. In this study ${ }^{16}$ gait and balance exercises in DPN participants resulted in longer strides, a shorter stride time and shorter stance phase duration measured during preferred gait velocity. We did not observe an effect of training at the preferred gait velocity, as both the intervention and control group increased their gait velocity over time. The training did however result in a longer stride length, stride time and stance phase duration during the imposed gait velocity, which is in part in line with the aforementioned study. ${ }^{16}$ If and to which extent these changes in spatiotemporal gait characteristics result in subjective improvement of walking quality and a more stable walking pattern needs to be determined in future studies. 
Over a period of 52 weeks we observed several changes in joint moments in both groups which could at least in part be explained by changes in gait velocity. During the preferred gait velocity, the joint moments for hip extension and flexion, knee extension and ankle plantar flexion at $40 \%$ of the stance phase all increased. As shown earlier in healthy young adults, hip extension and flexion moments increase with a faster gait velocity. ${ }^{17}$ Using the equations of this aforementioned study, more than $50 \%$ of the changes in joint moments in our participants could be explained by the increase in gait velocity. In addition, our participants also had an increase of knee extension moment and a decrease of knee flexion moment over time, which is difficult to explain based on the current data. More detailed studies are needed to explore the mechanisms underlying these changes over time and in particular to what extent these changes are related to progression of the underlying neuropathy.

In addition to effects of the training on spatiotemporal gait characteristics, we also observed a time-dependent effect, independent of the training. Longitudinal data on the walking pattern in DPN patients are scarce. Over the period of 52 weeks, participants of both the intervention and control group preferred to walk faster. Also other authors noted an increase in preferred gait velocity regardless of an intervention. ${ }^{18,19}$ It is likely that participants walking at a gait track for the first time decrease their preferred gait velocity due to unfamiliarity with the test settings. Peripheral sensory loss due to DPN could further contribute to this less confident gait pattern ${ }^{20}$ and the more often participants are measured the more familiar they become with the test track, resulting in a larger stride length and an increased gait velocity. Our patients with a slow preferred gait velocity seem to be more often in a poorer health condition and therefore more vulnerable, possibly contributing to a higher likelihood of dropping out. Consequently, the increase of gait velocity in our patients over time could be the result of selective dropout.

The current study clearly has some limitations; the attrition rate was high for both the intervention and control group and the pattern of missingness in the statistical analyses indicates that participants measured were not per definition a random selection of the group. The high dropout rate is a known problem for long-term exercise programs in patients with diabetes, eg, a dropout rate of $60 \%$ was observed during brisk walking program. ${ }^{21-23}$ In the current study the problem of missingness is, at least partly, circumvented by the application of the mixed model. Nevertheless, statistical significant differences need to be considered with caution. Furthermore, we did not correct for multiple testing, but several spatiotemporal gait characteristics changed in parallel, suggesting that gait characteristics can be influenced by training.

The current study provides valuable information for future longitudinal studies on strength training and gait analysis in participants with DPN. The study showed that these patients have a high risk for dropout, due to the underlying pathology and comorbidities. Hence, future studies should preferably first focus on participants with a relatively good health status and early neuropathy. The highest dropout rate was observed during the first 12 weeks of the program in both the intervention and control group and several participants reported lack of motivation as reason for dropping out. Lack of physical activity is an important factor in the development of type 2 diabetes and its complications. ${ }^{24,25}$ Future studies should focus on exploring the effect of motivational factors on exercise compliance in DPN, delineating these factors and find new ways to coach our patients in improving their mobility. However, it should be noted that strict selection of participants also has a drawback, as results might be less generalizable to the population of DPN patients. Secondly, as in the current study 16 patients were not able to safely walk over the test track at $1.2 \mathrm{~m} / \mathrm{s}$, future studies on gait in DPN patients might consider a slower standardized gait velocity. Finally, the increase of gait velocity over time should be accounted for in future studies, given the importance of gait velocity for joint moments or spatiotemporal gait characteristics.

It is concluded that strength training did not affect the maximal amplitude of hip, knee and ankle joint moments, and did increase stride length, stride time and stance phase duration in patients with DPN walking at a standardized, imposed, gait velocity, but the underlying mechanisms are unclear. More specified research exploring the effects of similar or other interventions is necessary. Future studies should focus on defining the motivational and health status related factors that will affect the outcome of the clinical trials on the effect of these training programs before their feasibility and effectiveness can be tested in patients with DPN.

\section{Acknowledgments}

The contributions of P. Hermkes, A. Toorians, and H. van Vroenhoven in recruitment and data acquisition are highly appreciated. Funding: Dutch Diabetes Federation and ZonMw.

\section{References}

1. Caselli A, Pham H, Giurini JM, Armstrong DG, Veves A. The forefoot-to-rearfoot plantar pressure ratio is increased in severe diabetic neuropathy and can predict foot ulceration. Diabetes Care. 2002;25(6):1066-1071. PubMed doi:10.2337/diacare.25.6.1066

2. Abboud RJ, Rowley DI, Newton RW. Lower limb muscle dysfunction may contribute to foot ulceration in diabetic patients. Clin Biomech (Bristol, Avon). 2000;15(1):37-45. PubMed doi:10.1016/S02680033(99)00038-8

3. Kwon OY, Minor SD, Maluf KS, Mueller MJ. Comparison of muscle activity during walking in subjects with and without diabetic neuropathy. Gait Posture. 2003;18(1):105-113. PubMed doi:10.1016/ S0966-6362(02)00166-2

4. Savelberg HH, Ilgin D, Angin S, Willems PJ, Schaper NC, Meijer K. Prolonged activity of knee extensors and dorsal flexors is associated with adaptations in gait in diabetes and diabetic polyneuropathy. Clin Biomech (Bristol, Avon). 2010;25(5):468-475. PubMed doi:10.1016/j. clinbiomech.2010.02.005

5. Savelberg HH, Schaper NC, Willems PJ, de Lange TL, Meijer K. Redistribution of joint moments is associated with changed plantar pressure in diabetic polyneuropathy. BMC Musculoskelet Disord. 2009;10:16. PubMed doi:10.1186/1471-2474-10-16

6. Melai T, Schaper NC, IJzerman TH, et al. Increased forefoot loading is associated with an increased plantar flexion moment. Hum Mov Sci. 2013; in press. PubMed

7. Allet L. H IJ, Meijer K, Willems P, Savelberg H. The influence of stridelength on plantar foot-pressures and joint moments. Gait Posture. 2011;34(3):300-306. PubMed doi:10.1016/j.gaitpost.2011.05.013

8. Courtemanche R, Teasdale N, Boucher P, Fleury M, Lajoie Y, Bard C. Gait problems in diabetic neuropathic patients. Arch Phys Med Rehabil. 1996;77(9):849-855. PubMed doi:10.1016/S00039993(96)90269-5

9. Mueller MJ, Minor SD, Sahrmann SA, Schaaf JA, Strube MJ. Differences in the gait characteristics of patients with diabetes and peripheral neuropathy compared with age-matched controls. Phys Ther. 1994;74(4):299-308; discussion 309-213.

10. Valk GD, de Sonnaville JJ, van Houtum WH, et al. The assessment of diabetic polyneuropathy in daily clinical practice: reproducibility and 
validity of Semmes Weinstein monofilaments examination and clinical neurological examination. Muscle Nerve. 1997;20(1):116-118. PubMed doi:10.1002/(SICI)1097-4598(199701)20:1<116::AIDMUS19>3.0.CO;2-2

11. Chetlin RD, Gutmann L, Tarnopolsky M, Ullrich IH, Yeater RA. Resistance training effectiveness in patients with Charcot-MarieTooth disease: recommendations for exercise prescription. Arch Phys Med Rehabil. 2004;85(8):1217-1223. PubMed doi:10.1016/j. apmr.2003.12.025

12. Andersen H, Schmitz O, Nielsen S. Decreased isometric muscle strength after acute hyperglycaemia in Type 1 diabetic patients. Diabet Med. 2005;22(10):1401-1407. PubMed doi:10.1111/j.14645491.2005.01649.x

13. Moisio KC, Sumner DR, Shott S, Hurwitz DE. Normalization of joint moments during gait: a comparison of two techniques. J Biomech. 2003;36(4):599-603. PubMed doi:10.1016/S0021-9290(02)00433-5

14. Delbridge L, Perry P, Marr S, et al. Limited joint mobility in the diabetic foot: relationship to neuropathic ulceration. Diabet Med. 1988;5(4):333-337. PubMed doi:10.1111/j.1464-5491.1988. tb01000.x

15. van Deursen RW, Sanchez MM, Ulbrecht JS, Cavanagh PR. The role of muscle spindles in ankle movement perception in human subjects with diabetic neuropathy. Exp Brain Res. 1998;120(1):1-8. PubMed doi:10.1007/s002210050371

16. Allet L, Armand S, Aminian K, et al. An exercise intervention to improve diabetic patients' gait in a real-life environment. Gait Posture. 2010;32(2):185-190. PubMed doi:10.1016/j.gaitpost.2010.04.013

17. Lelas JL, Merriman GJ, Riley PO, Kerrigan DC. Predicting peak kinematic and kinetic parameters from gait speed. Gait Posture. 2003;17(2):106-112. PubMed doi:10.1016/S0966-6362(02)00060-7

18. Tsang T, Orr R, Lam P, Comino EJ, Singh MF. Health benefits of Tai Chi for older patients with type 2 diabetes: the "Move It For Diabetes study"- - a randomized controlled trial. Clin Interv Aging. 2007;2(3):429-439. PubMed

19. Orr R, Tsang T, Lam P, Comino E, Singh MF. Mobility impairment in type 2 diabetes: association with muscle power and effect of Tai Chi intervention. Diabetes Care. 2006;29(9):2120-2122. PubMed doi: $10.2337 / \mathrm{dc} 06-1130$

20. Menz HB, Lord SR, St George R, Fitzpatrick RC. Walking stability and sensorimotor function in older people with diabetic peripheral neuropathy. Arch Phys Med Rehabil. 2004;85(2):245-252. PubMed doi:10.1016/j.apmr.2003.06.015

21. Monteiro MA, Gabriel RE, Neves ECM, Sousa MF, Abrantes JM, Moreira MH. Exercise effects in plantar pressure of postmenopausal women. Menopause. 2010;17(5):1017-1025. PubMed doi:10.1097/ gme.0b013e3181ddf6ef

22. Praet SF, van Rooij ES, Wijtvliet A, et al. Brisk walking compared with an individualised medical fitness programme for patients with type 2 diabetes: a randomised controlled trial. Diabetologia. 2008;51(5):736-746. PubMed doi:10.1007/s00125-008-0950-y

23. Thoolen B, de Ridder D, Bensing J, Gorter K, Rutten G. Who participates in diabetes self-management interventions?: Issues of recruitment and retainment. Diabetes Educ. 2007;33(3):465-474. PubMed doi:10.1177/0145721707301491

24. Gill JM, Cooper AR. Physical activity and prevention of type 2 diabetes mellitus. Sports Med. 2008;38(10):807-824. PubMed doi:10.2165/00007256-200838100-00002

25. Hu FB, Leitzmann MF, Stampfer MJ, Colditz GA, Willett WC, Rimm EB. Physical activity and television watching in relation to risk for type 2 diabetes mellitus in men. Archives of Internal Medicine. 25 2001;161(12):1542-1548.

\section{Appendix}

\section{Training Program}

The training program was designed based on a study by Chetlin et al (2004) and multidisciplinary consensus. It lasted 24 weeks, with 3 training sessions per week. Once a week there was a plenary training, consisting of four sections: a warm-up, strength and balance training, gait training and adjusted games. Apart from this plenary training the participants were asked to continue the strength training twice a week at home during 30 minutes.

\section{Warm-Up}

The warm-up was the same every week, lasted for approximately 10 minutes and consisted of walking laps in the training hall at an individual pace. During walking various assignments were given:

- Stand still and stretch as far as you can: arms as high as possible over your head while standing on your toes;

- Stand still and "roll down" starting with your head, vertebra by vertebra;

- Swing your arms and spin around;

- Walk on your toes:

- Walk on your heels;

- Walk with long steps;

- Walk with wide steps;

- Tap your heels against your buttocks;

- Pull up your knees;

- Shake loose your arms and legs.

\section{Strength and Balance Training}

The strength and balance training was performed sitting on a chair (during most exercises) with a duration of 25 minutes. The exercises were performed with constant resistance during 4 weeks. The first week started out with 3 sets of 4 repetitions. This was increased by 2 repetitions per week until 3 sets of 10 repetitions were performed in the fourth week. After the fourth and eight week the exercise resistance was increased and the participants started with 3 sets of 4 repetitions again, followed by the same schedule. The schedule is schematically presented in a table:

\begin{tabular}{lcccc}
\hline & \multicolumn{4}{c}{ Week } \\
\cline { 2 - 5 } & $\mathbf{1 / 5 / 9}$ & $\mathbf{2 / 6 / 1 0}$ & $\mathbf{3 / 7 / 1 1}$ & $\mathbf{4 / 8 / 1 2}$ \\
\cline { 2 - 5 } $\begin{array}{l}\text { Number of Series } \\
\times \text { Repetitions: }\end{array}$ & $3 \times 4$ & $3 \times 6$ & $3 \times 8$ & $3 \times 10$ \\
\hline
\end{tabular}

The strength and balance training consisted of two components. During the first 12 weeks of the training program it was mainly aimed at the muscles around the ankle; the exercises were as follows:

- Resisted plantar flexion. Participant standing up, if necessary supported by a chair. Heel raises with repeatedly standing on toes.

- Coordination of the lower leg muscles. Participant folds and unfolds a towel with feet while sitting on a chair.

- Resisted foot eversion. Participant sits, secures elastic band with predetermined resistance around balls of feet. Feet are placed at hip width on the heels, participant turns the right foot repeatedly from neutral position to eversion and back. 
- Balance and stability exercises. Participants in twos, one performs the exercise, the other assists and offers support if necessary. Participant is standing behind a chair, feet at hip width, closes the eyes and stays standing, if possible without support. In the course of the weeks the difficulty level is increased by standing on one leg and finally to standing on one leg with eyes closed.

- Balance and stability exercises. Participants in twos, one performs the exercise, the other assists and offers support if necessary. Participant is standing behind a chair, feet approximately at hip width, lifts feet off the floor and holds the knee in $90^{\circ}$ flexion, closes eyes, if possible without taking support.

- Resisted dorsiflexion and plantar flexion. Participant sits, secures elastic band with predetermined resistance around balls of feet. Participant places heels on the floor, ankle in approximately $90^{\circ}$, the right foot moves toward plantar flexion and back, the left foot is kept still.

- Resisted dorsiflexion and plantar flexion of the foot. Participants in twos, sitting across from each other. One secures elastic band with predetermined resistance around the forefoot, while the other secures both ends under the foot. The first participant moves the foot repeatedly toward dorsiflexion and back to a $90^{\circ}$ angle.

The second component took place during weeks 13 until 24 and was aimed at strengthening the entire leg; the exercises were as follows.

- Strength training of the hip and knee extensors. Participant sitting with elastic band with predetermined resistance under the right foot, the two ends secured in his or her hands. Starting with the knee at the chest, the leg is repeatedly extended toward the floor and slowly back to the starting position.

- Strength training of the hip and knee extensors. Participant standing in front of a step bench or comparable bench. Participant steps with one foot on the bench followed by the other foot. Then both feet return to the starting position.

- Strength training of the hip and knee extensors. Participants squat starting from a standing position (move buttock backward to relieve the knees), as if they want to pick something up from the floor. Then back to a standing position.

- Strength training of the hip and knee extensors. Participants standing with chair approximately $1 \mathrm{~m}$ in front of them. Participants make lunges forward, alternating right and left leg. Both legs are flexed, the knee of the hind leg in an angle of approximately $90^{\circ}$, with the knee moving toward the floor.

- Strength training of the hip and knee extensors. Participants sitting. Starting from this position each participant moves toward a full standing position, without using the arms/hands, and back to a sitting position. To ensure that the participants are actually sitting down, they must place a cone from the left side of the chair to the right side, or vice versa.

- Strength training of the hip adductors. Participant sitting with soft ball between the knees, the hands are kept on the back.
Participant squeezes the ball empty between the knees, and slowly lets it inflate again.

- Strength training of the hip abductors. Participants sitting with elastic band with predetermined resistance is knotted closefittingly around the knees. The feet are approximately at hip width on the floor. The knees are alternately pulled away from each other and slowly back toward each other.

- Strength training of the knee flexors. Participants sitting with ball under the heel. Both hands are kept on the back, the ball is pressed flat with the foot, then slowly allowed to inflate.

\section{Gait Training}

A gait training was offered during thirty minutes in the form of an exercise track, resulting in coordination training on a functional level.

- Diagonal ramp: ramp is diagonal to the walking direction (imitates slopes).

- Balance beam: path of $6 \mathrm{~m}$ long, $15 \mathrm{~cm}$ broad, two bends at right angles. The feet must be placed entirely on the strip while walking over the path.

- Walking on various surfaces (soft mattress, deep-pile carpet, grass, sand, rubber mats, foam rubber).

- Climbing a ramp, turn and back down: 2-3 benches attached to the wall bars next to each other at an obtuse angle (supervised).

- Cones are placed around the ends of a bench: participant walks in between the bench and the cones (imitates small passage, eg, around a coffee table).

- Picking up balls from a box on the ground, bring it to another box.

- Stepping over a bench.

- Stepping stones: participant walks the track with long paces.

- Slalom: 6 cones with a stick standing in them, walk between them without touching the sticks or cones.

- Pirouette: on a disk with a diameter of $40 \mathrm{~cm}$, turn 360 degrees without moving off the surface of the disk.

- Sitting down and standing up without arm support, chair is $35 \mathrm{~cm}$ high. To ensure that the participants are actually sitting down, they must place a cone from the left side of the chair to the right side while sitting down, and vice versa.

- Walking while pushing a ball continuously with the foot, without losing control of the ball.

\section{Games}

Each plenary training session was concluded with fifteen minutes of interactive games, such as volleyball, badminton or basketball. Because of the decreased load tolerance of the participants the games were adjusted, such as by replacing the ball with a balloon or beach ball. 